\title{
Using perceptions as evidence to improve conservation and environmental management
}

\author{
Nathan James Bennett ${ }^{12}$
}

This is a post-print version of a published article. Please cite as:

Bennett, N. J. (2016) Using perceptions as evidence to improve conservation and environmental management. Conservation Biology. In press.

\begin{abstract}
The conservation community is increasingly focusing on the monitoring and evaluation of management, governance, ecological, and social considerations as part of a broader move toward adaptive management and evidence-based conservation. Evidence is any information that can be used to come to a conclusion and support a judgment or, in this case, to make decisions that will improve conservation policies, actions, and outcomes. Perceptions are one type of information that is often dismissed as anecdotal by those arguing for evidence-based conservation. In this paper, I clarify the contributions of research on perceptions of conservation to improving adaptive and evidence-based conservation. Studies of the perceptions of local people can provide important insights into observations, understandings and interpretations of the social impacts and ecological outcomes of conservation; the legitimacy of conservation governance; and the social acceptability of environmental management. Perceptions of these factors contribute to positive or negative local evaluations of conservation initiatives. It is positive perceptions, not just objective scientific evidence of effectiveness, that ultimately ensure the support of local constituents thus enabling the long-term success of conservation. Research on perceptions can inform courses of action to improve conservation and governance at scales ranging from individual initiatives to national and international policies. Better incorporation of evidence from across the social and natural sciences and integration of a plurality of methods into monitoring and evaluation will provide a more complete picture on which to base conservation decisions and environmental management.
\end{abstract}

Keywords: perceptions, monitoring and evaluation, evidence-based conservation, conservation social science, environmental social science, protected areas, environmental governance, environmental management, adaptive management

\footnotetext{
${ }^{1}$ Institute for Resources, Environment and Sustainability, University of British Columbia, 2202 Main Mall, Vancouver, BC V6T 1Z4, Canada

${ }^{2}$ School of Marine and Environmental Affairs, University of Washington, Seattle, Washington, 98105, U.S.A.
}

•Email: nathan.bennett@ubc.ca; Website: http://nathanbennett.ca 


\section{Improving conservation with evidence}

The effectiveness of conservation is a pressing global concern. The Convention on Biological Diversity (CBD) Aichi Target 11 requires that protected area networks be "effectively and equitably managed" (CBD 2010). Yet numerous studies and reviews show that the implementation of a conservation initiative is no guarantee of ecological success (Mora \& Sale 2011; Pfeifer et al. 2012; Ferraro et al. 2013; Edgar et al. 2014) or of benefit to humans (West et al. 2006; Coad et al. 2008; Bennett \& Dearden 2014a). This concern that conservation is ineffective is leading to increased monitoring and evaluation of management, governance, ecological, and social considerations as part of a broader move toward adaptive management and evidence-based conservation.

In recent years, there has been considerable emphasis in conservation policy and programs on monitoring and evaluation. For example, there are several well-established and widely employed frameworks for evaluating management effectiveness in marine and terrestrial protected areas (Pomeroy et al. 2004; Hockings et al. 2006). The CBD Programme of Work on Protected Areas calls for the "assessment of the economic and socio-cultural costs, benefits and impacts" of protected areas (CBD 2004), and the last decade has seen a proliferation of methods and manuals for monitoring the social impacts of conservation ( Schreckenberg et al. 2010). Several international programs that monitor social impacts of conservation have been launched (e.g., the Global Socioeconomic Monitoring Initiative for Coastal Management [Bunce et al. 2000; SOCMON 2015] and the Social Assessment of Protected Areas initiative [Schreckenberg et al. 2010]). The International Union for the Conservation of Nature produced a series of policy documents urging a greater focus on evaluating the governance of protected areas (BorriniFeyerabend et al. 2007, 2013). Indicators of social and governance factors have also been incorporated in the aforementioned management effectiveness frameworks.

The increased attention to monitoring and evaluation is part of a broader trend toward evidence-based conservation (Sutherland 2003; Sutherland et al. 2004; Mathevet \& Mauchamp 2005; Ferraro \& Pattanayak 2006; Segan et al. 2011; Miteva et al. 2012; Pullin et al. 2013; Cook et al. 2013) which is accompanied by bold claims that engaging a medical model of evaluation will cure conservation (Wilkie \& Ginsberg 2014). The goal of evidence-based conservation is to ensure that impartial decisions are made at all stages of conservation planning, implementation, and management based on objective scientific information (Sutherland et al. 2004; Segan et al. 2011; Pullin et al. 2013). Advocates argue that evidence is integral to creating more effective conservation decisions through adaptive management, which involves a cycle of planning, implementing, monitoring, evaluating, and adapting conservation actions to improve outcomes (Hockings et al. 2006).

Good evidence is clearly necessary for making conservation decisions. However, there are several problems with current calls for and framings of evidence-based conservation that need to be acknowledged and addressed. First, preference is given to certain types of knowledge, methods, and information. In social-impact assessment, for example, there is an increasing emphasis on quantitative methods stemming from the econometric tradition (Ferraro \& Pattanayak 2006; Andam et al. 2010; Ferraro \& Hanauer 2014). The prominence given to quantitative and objective methods is not surprising given the broader privileging of positivistic science in Western society and in the field of conservation (Evely et al. 2008; Moon \& Blackman 2014). Yet these focused methods, which are incredibly useful for answering some types of questions, can lead to an incomplete picture of the complex and messy social, political, and economic contexts within which conservation occurs (Adams \& Sandbrook 2013). Without 
employing a wide array of approaches and methods from across the social sciences (including sociology, anthropology, psychology, geography, economics, political science, and development studies) and the natural sciences, important contextual factors may be obscured and inadequate contextual understandings may lead to culturally inappropriate, socially unjust, or untenable conservation actions (Corson \& MacDonald 2012; Bennett et al. 2015).

Second, the data and knowledge required and the costs associated with many quantitative and longitudinal monitoring and evaluation protocols may hinder the ability of managers in many contexts to collect, analyze, and apply the results in a meaningful fashion (Jones 2012). These capacity deficits may thus require increased reliance on outside academics and consultants to carry out the monitoring and analysis. Lack of local participation in monitoring and evaluation can also lead to lost opportunities for building capacity, coproducing knowledge, promoting buyin, and ensuring appropriateness of and support for recommendations (Gujit 1999; Evans \& Guariguata 2008; Fortmann 2008; Chevalier \& Buckles 2013).

Third, the length of time associated with doing quantitative and longitudinal analysis of social and ecological outcomes may result in recommendations that are too little and too late. Furthermore, the current methods provide limited insights into what governance blunders or management shortcomings are leading to which outcomes (Bennett \& Dearden 2014b). For example, lack of participation or consideration of local context, values, and needs can produce distrust or resistance (Chuenpagdee et al. 2013) - concerns that might be easily caught through rapid or participatory appraisals. Additionally, a simple analysis of the presence or absence of input variables (i.e., policies, resources, and actions) should precede or complement the measurement of ecological and social outcomes (Bennett \& Dearden 2014b).

Finally, although a culture of auditing has emerged in the conservation community, it remains unclear whether monitoring and evaluation programs are actually leading to succinct, accessible, effectively communicated, and clearly articulated recommendations that will improve conservation policies, actions, or outcomes. These issues may lead one to reflect on numerous challenging questions, including what formats should monitoring and evaluation protocols take in different contexts and at different stages of conservation?; when are the predominant quantitative evaluations of conservation initiatives advisable and sufficiently informative to be a worthwhile investment?; what other forms of evidence are valuable for making conservation decisions?; when are other forms of evidence complementary or as or more valuable for guiding conservation actions?; and how can one ensure results are communicated in an accessible and usable manner and applied in the real world?

The goal is not just more and better science; rather, the goal is enhanced conservation actions and outcomes. To achieve this goal, it is critical to be clear about the role, potential and limitations of all forms of evidence to improve understanding and inform conservation policy and practice. Producing effective conservation actions and outcomes requires a broad view of conservation science (Kareiva \& Marvier 2012; de Snoo et al. 2013; Bennett \& Roth 2015). I define conservation science as the systematic study of ecological, social, and integrated socialecological phenomena to document empirical information for the purposes of conservation. In general terms, evidence is any information that helps one formulate a conclusion or support a judgment. In conservation science, a pluralistic view of evidence might include rigorously produced quantitative or qualitative ecological or social data as well as local and traditional knowledge - all of which can be used to guide or improve conservation policies, management actions, and ecological outcomes (Pullin et al. 2013; Adams \& Sandbrook 2013). Yet for many of the natural and social scientists advocating for increased monitoring and evaluation, evidence- 
based conservation, or adaptive management, perceptions are often dismissed as "anecdotal evidence" that may be based on inaccurate "experiential knowledge" or "myths" (Sutherland et al. 2004; Ferraro 2008; Pullin \& Salafsky 2010; Adams \& Sandbrook 2013; Legge 2015). Rather than being dismissive of some forms of evidence, a pragmatic approach to conservation science requires considering all disciplines and methods when seeking to understand conservation issues and all available information in the search for effective solutions.

In this paper, I clarify the contributions of research on local perceptions of conservation to improving knowledge and practice of conservation, as part of monitoring and evaluation programs, adaptive management processes, and evidence-based conservation decision making. My broader aim is to highlight the importance of incorporating the full range of evidence from across the social and natural sciences and of using multiple methods in monitoring and evaluation protocols to provide a more complete picture on which to base conservation and environmental management decisions.

\section{Research on perceptions of conservation}

The term perceptions is often used by researchers studying environmental management and conservation (Webb et al. 2004; Christie 2005; McClanahan et al. 2005; Xu et al. 2006; Dalton et al. 2012; Leleu et al. 2012; Eagles et al. 2013; Bennett \& Dearden 2014a; Cinner et al. 2014; Turner et al. 2014; McClanahan \& Abunge 2015). Yet researchers often simply use the term as shorthand for positive or negative evaluations of some aspect of conservation (e.g., governance, management, impacts on resources, costs and benefits) or of the entire conservation initiative. Furthermore, no article that I am aware of clearly articulates the set of insights provided by the study and monitoring of local perceptions of conservation that may aid conservation policy and practice. As a social science concept, perceptions is often more loosely applied than related and highly theorized concepts such as beliefs, attitudes, values, norms, preferences, and motivations, but all are linked as determinants or moderators of behaviors, responses, and levels of support (Ajzen 1991; Slovic 2000; Stern 2000; Manfredo et al. 2004; Schultz 2011; Clayton et al. 2013; Klöckner 2013). Drawing on established definitions in (Munhall 2008; Oxford Dictionary 2015) and examination of the extensive literature on conservation and risk in which the term is used, I propose the following definition: perceptions refers to the way an individual observes, understands, interprets, and evaluates a referent object, action, experience, individual, policy, or outcome. Observations are based on sensory experiences, including sight, hearing, smell, touch and taste. These individual and subjective interpretations of reality are socially constructed, the product of one's history and surroundings (Munhall 2008). A myriad of contextual factors (e.g., culture, politics, socioeconomics, livelihoods), past experiences of similar events (e.g., imposition of a different environmental policy), and individual and collective attributes (e.g., gender, race), values, norms, beliefs, preferences, knowledge, and motivations mediate and influence perceptions (Slovic 2000; Munhall 2008; Satterfield et al. 2009; Moon \& Blackman 2014; Levine et al. 2015). As a result, like and unlike groups and individuals can perceive the same situation in vastly different ways. Perceptions can also change over time, and judgments are subject to persuasion (Satterfield et al. 2009). Finally, perceptions can be based on knowledge but should not be confused with the "experiential knowledge" of scientific experts or traditional resource users (Fazey et al. 2006).

There are at least 4 distinct categories of insights that studies of local perceptions can provide to improve conservation policy and practice: social impacts of conservation, ecological outcomes of conservation, legitimacy of conservation governance, and acceptability of 
conservation management (Table 1). First, research on perceptions can be used to explore the nature and magnitude of social impacts and to discern whether local people view the social impacts of conservation as just or equitable. Conservation initiatives are often criticized for the unjust social and economic impacts that they can have on local communities and livelihoods (Brockington et al. 2006; West et al. 2006). Just as often, the benefits of conservation are expounded (Leisher et al. 2007; Andam et al. 2010). Local perceptions of the impacts of conservation can be determined by exploring narrative descriptions of social impacts or by rating quantitative indicators of livelihoods, assets, wealth and poverty, well-being, food security, or rights (Cattermoul et al. 2008; Bennett et al. 2012; Weeratunge et al. 2014). A sense of injustice or inequity - in either net social costs versus benefits to a collective or in the distribution of costs and benefits between subgroups - can go a long way in determining support for conservation (Klain et al. 2014; Pascual et al. 2014). For example, individuals or groups who observe or believe they are not receiving an equitable share of the benefits of conservation or their rights or cultural values have been undermined may actively oppose conservation (Kemf 1993; Bennett et al. 2010). This is true even when local people support the ideals of protecting nature or increasing the abundance of species or resources (Bennett \& Dearden 2014a).

Table 1. Use of perceptions as evidence to improve conservation.

\begin{tabular}{|l|l|}
\hline \multicolumn{1}{|c|}{ Category of perceptions } & \multicolumn{1}{c|}{ Basis of evaluation } \\
\hline $\begin{array}{l}\text { Social impacts of } \\
\text { conservation }\end{array}$ & $\begin{array}{l}\text { - nature and magnitude of social impacts (costs and benefits); } \\
\text { - equity in distribution of social costs and benefits }\end{array}$ \\
\hline $\begin{array}{l}\text { Ecological outcomes of } \\
\text { conservation }\end{array}$ & $\begin{array}{l}\text { - impacts on environmental quality and productivity; } \\
\text { - impacts on provisioning of ecosystem services and benefits. }\end{array}$ \\
\hline $\begin{array}{l}\text { Legitimacy of } \\
\text { conservation governance }\end{array}$ & $\begin{array}{l}\text { - quality of governance processes; } \\
\text { - appropriateness and inclusiveness of governance structures; } \\
\text { - legitimacy of policies, rules, and decision makers; }\end{array}$ \\
\hline $\begin{array}{l}\text { Acceptability of } \\
\text { conservation management }\end{array}$ & $\begin{array}{l}\text { - presence or absence of management inputs; } \\
\text { - appropriateness of conservation models; } \\
\text { - acceptability of management actions; } \\
\text { - quality of engagements with conservation managers }\end{array}$ \\
\hline
\end{tabular}

Second, local resource users and communities may evaluate conservation initiatives and levels of support for conservation based on their perceptions of the ecological impacts of conservation (e.g., abundance of individual species, productivity of harvests or quality of habitats) and related benefits to themselves, their households, or their communities via ecosystem services. Of course, the accuracy of individual assessments of resource abundance or ecosystem health may vary widely within a community. For example, one might differentiate between the perceptions of those with expert knowledge and perceptions of non-experts in a community (Fazey et al. 2006). Community experts include traditional or multi-generational resource users (e.g., fishers, hunters) who have amassed traditional ecological knowledge (TEK) (i.e., a cumulative body of knowledge about the local environment that is intergenerational and collective [Berkes 1999]) of local ecosystems or species. Those with high levels of TEK will likely be able to assess more accurately changes in the status of natural resources (Berkes et al. 2000; Johannes et al. 2000). For example, local fishers may be the first to observe benefits, or lack thereof, to fisheries from marine protected areas (e.g., Cinner et al. 2014). Whereas some 
authors question the accuracy of TEK or the knowledge of local resource users (Christie 2005; Daw et al. 2011; Leleu et al. 2012), it was not my aim here to compare the validity of scientific research versus TEK in assessing ecological status and outcomes. Whether TEK is accurate or not, the assessments of local knowledge holders regarding the ecological impacts of conservation will shape their perceptions of and support for conservation initiatives (Webb et al. 2004; Leleu et al. 2012). The support of other non-expert community members (i.e., those who are not direct resource users and do not possess high levels of TEK) can also rely on perceived ecological impacts and the quality and quantity of benefits received from changes to ecosystem services (e.g., provisioning of food sources [e.g., wild meat, fish], protection of shorelines and community infrastructure, or maintenance of culturally important species or sacred sites) resulting from conservation (Silvano et al. 2005; Rönnbäck et al. 2007; Fox et al. 2012). For example, women who do not fish may experience changes in household food sources and security due to changes in the quality, size, or abundance of fish. The presence of mangroves and their effects on erosion and infrastructure is also readily understood by individuals living in coastal communities. Whether knowledge and perceptions are accurate or not, in diverse communities that are often concerned about the state of the local environment, observations of ecological status and opinions related to environmental benefits from conservation are vitally important for producing a supportive constituency for conservation.

Third, perceptions can be used to assess how constituents appraise the legitimacy of governance. Governance refers to the structures, institutions, and processes that determine who makes decisions, how decisions are made, and how actions are taken to solve social and environmental problems (Graham et al. 2003; Bennett 2015). The functioning of conservation governance can be evaluated based on indicators of norms such as participation, transparency, accountability, flexibility, collaboration, leadership, vision, and communication (Lockwood 2010; Eagles et al. 2013; Bennett \& Dearden 2014b). For example, entire communities or some groups might believe their participation is inadequate if they were not consulted during the creation of a protected area, if they were marginalized in decision making, or if the quality of processes was poor (Berlanga \& Faust 2007; Dalton et al. 2012). Perceptions of whether governance processes are contextually appropriate and whether the individuals responsible for governance are worthy of support can lead to support of or opposition to conservation.

Finally, perceptions can convey important details about the social acceptability and appropriateness of management inputs, models, actions, and managers. The social acceptability of particular conservation policies (e.g., marine protected areas), conservation initiatives (e.g., creation of an exclusive hunting reserve), or management actions (e.g., allowing tourists to enter a sacred site) differ by social, cultural, political, and economic contexts. For example, the exclusionary models of conservation that are acceptable to some may not align with indigenous cultural values or ways of seeing nature as part of integrated social-ecological systems (Berkes 1999; Pilgrim \& Pretty 2010; Gavin et al. 2015). Additional factors that may determine the acceptability of management actions include levels of local dependence on resources for livelihoods (Webb et al. 2004; Svensson et al. 2010); inclusion of vulnerable or underrepresented groups, such as women (Walker \& Robinson 2009); cultural meanings associated with resources or certain areas (Bennett et al. 2010); incorporation of preexisting or envisioned management or governance processes (Ferse et al. 2010; Klain et al. 2014); consideration of local voices, opinions, and perspectives (Oracion et al. 2005); knowledge of the conservation initiative (Leleu et al. 2012); respectful integration of TEK (Drew 2005); and the way individual managers engage with individuals or the community (Bennett \& Dearden 2014a). 


\section{The study of perceptions}

Conservation initiatives and actions are a perpetual experiment. This trial-and-error view of conservation requires constant attention to successes and failures and subsequent adaptations of policies and actions to improve ecological and social outcomes. The goal of monitoring and evaluation is to determine what is working, what is not working, why, and what to do about it (Mascia et al. 2014). Evidence comes in many forms. Perceptions are an indispensable form of evidence that is useful at all stages of conservation from planning and implementation to ongoing management. Perceptions can and should be monitored to understand when evaluations of conservation are positive or negative and to assess what facets of a conservation initiative social impacts, ecological outcomes, governance, or management - are generating or undermining support and related actions (Fig. 1).

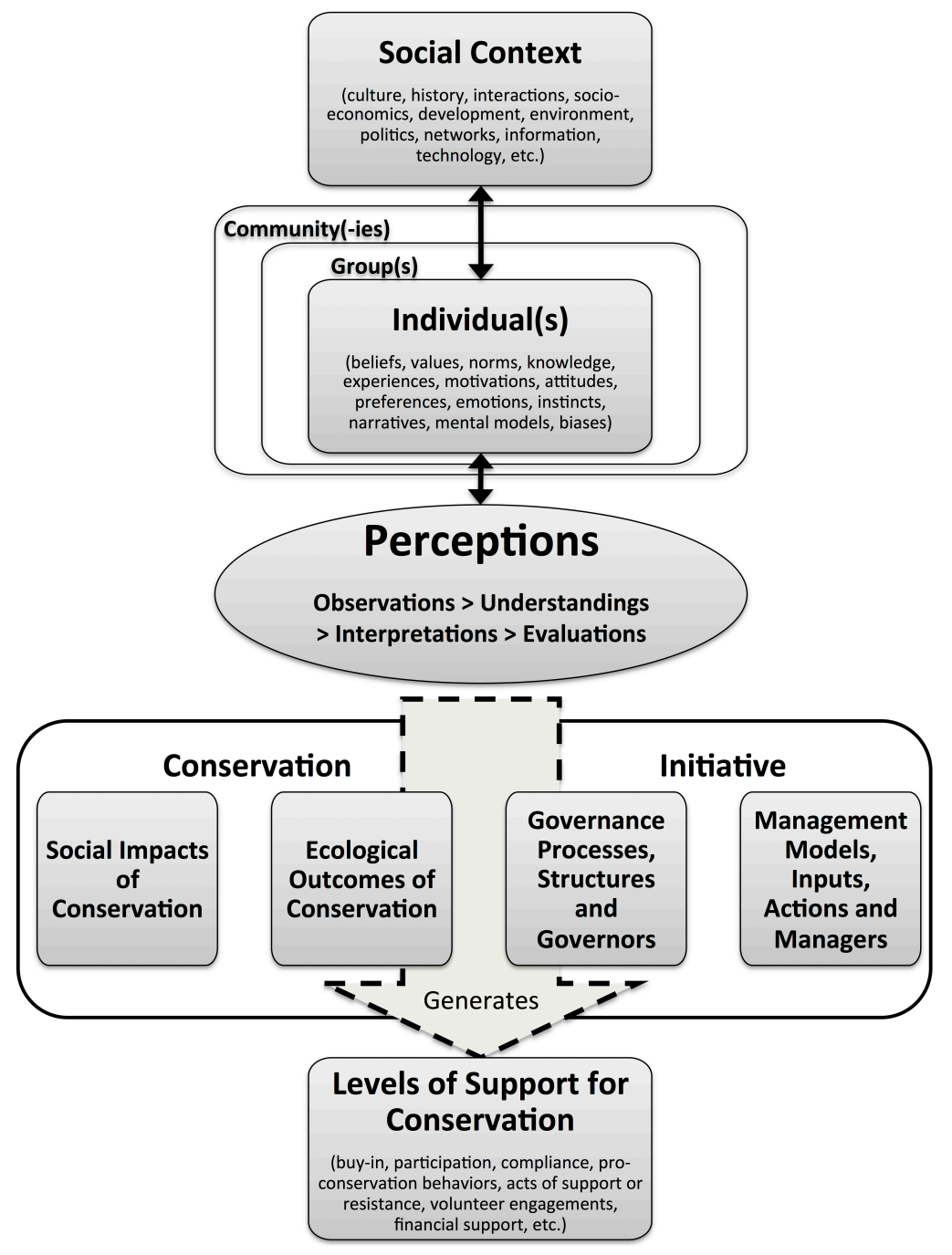

Figure 1. Contribution of perceptions to evaluations of conservation and generation of local support for conservation. 
To study perceptions, qualitative, participatory, and quantitative methods can be used. In the studies I reviewed for this paper, qualitative interviews and quantitative surveys were used most often to explore perceptions of conservation. Interviews allow for open-ended questions leading to nuanced understandings and rich narrative descriptions of perceptions from diverse perspectives (Ezebilo \& Mattsson 2010). More structured interviewing techniques may also be useful for understanding individual or collective perceptions of conservation. For example, Q method is a multistage structured interview method for dealing with subjectivity and identifying potential trade-offs between the perceptions of different groups (Webler et al. 2009). Using interviews to explore people's mental models (i.e., their understandings of the world) may also elucidate how people's experiences and perceptions shape their intentions, behaviors, or support for conservation (Biggs et al. 2011). Focus groups provide a similar level of richness and depth; however, facilitators need to ensure that all perspectives and voices are heard (Marcus 2001; Tobey \& Torell 2006). Numerous participatory (Chevalier \& Buckles 2013) and arts-based methods (e.g., photovoice or participatory video) are used to monitor and evaluate in an inclusive manner that leads to co-learning and whereby results are directly integrated into planning and deliberation processes (Gujit 1999; Evans \& Guariguata 2008). Surveys might be used to rate (e.g., using a Likert scale), rank (e.g., using multicriteria analysis), and compare (e.g., between groups, sites, countries) quantitative indicators of perceptions of social, ecological, governance, and management considerations (Webb et al. 2004; Christie 2005; Eagles et al. 2013; Gurney et al. 2014; Cinner et al. 2014). Whichever method is used, it is essential to go beyond understanding perceptions and seek closure of the cycle of adaptive management (i.e., planning, implementing, monitoring, evaluating, and adapting [Hockings et al. 2006]) by communicating results, exploring solutions, and providing recommendations. Closure will be aided by incorporating results into subsequent focus groups or stakeholder deliberations that explore rationales for positive or negative evaluations and implications for conservation policy and practice.

There are clear benefits to studying local perceptions of conservation. First, positive local perceptions are fundamental to the success of conservation. Although perceptions are not necessarily objective, they always represent a facet of the truth, and importantly for managers, individuals' subjective perceptions can become their truths (Munhall 2008). Perceptions, in the form of observations, understandings, and interpretations, can lead to positive or negative evaluations that exert a powerful influence on people's support for conservation (Figure 1). The in-depth study and analysis of perceptions can help determine the underlying causes of lack of support and identify relevant interventions to ensure long-term support and the success of conservation.

Second, the insights from research on perceptions can be quickly and easily incorporated into decision making or co-management processes when recommendations are clearly articulated and communicated to managers. For example, results may tell conservation practitioners or managers that actions need to be taken: to increase the socioeconomic benefits of conservation or the distribution of these benefits; to ensure that the ecological benefits of conservation are being generated and felt or received by intended beneficiaries or are apparent to stakeholders; to enhance the legitimacy of governance processes, structures, policies, or decision-makers; and to improve the presence or social acceptability of management actions.

Third, studies of perceptions do not involve some of the challenges of long-term quantitative monitoring and evaluation programs, including complex protocols and analyses, lack 
of local participation, loss of opportunities for co-learning, reliance on outside experts, limited support for long-term studies, and high costs.

There are also well-recognized limitations of research on perceptions. In particular, local perceptions are subjective and may not accurately represent outcome variables, such as the state of the environment (abundance of species or quality of habitats) (Christie 2005; Daw et al. 2011; Leleu et al. 2012), or may not be used to determine attribution or causal influence of conservation (e.g., effect of a protected area on local levels of poverty [Agrawal \& Redford 2006; Ferraro 2008; Ferraro \& Hanauer 2014]). In part, this is because perceptions are not produced in a vacuum of objectivity; they are highly mediated by past experiences and by personal motivations (e.g., for wealth, power, security of tenure, or the ability to feed one's family). The constructed nature of perceptions may also mean that self-reported perceptions are purposefully inaccurate. Yasue et al. (2010:407) suggest that differences between perceptions and scientific data of fish abundance inside and outside marine protected areas may be the result of "wishful thinking, external influences, [or] a desire to please" among other things. As discussed previously, individual's perceptions of social or ecological outcomes may also be negatively affected by unfavorable conservation management and governance processes. Finally, perceptions cannot be used to determine causality in the absence of counterfactual evidence achieved through longitudinal, pre- and post-implementation, or controlled studies (Ferraro 2008). For example, if the aim of a study is to make or verify very broad quantitative claims about whether protected areas cause poverty, then perceptions are not a suitable tool. Even longitudinal and control-based studies of perceptions cannot lead to attribution of objectively measurable outcomes; rather, they lead to assertions that perceptions have changed as a result of an initiative (Gurney et al. 2014).

In some situations and stages of conservation, knowledge of perceptions is particularly useful. Prior to implementation of a conservation initiative, during the planning phase, perceptions can be proactively examined to establish baselines, imagine the future social impacts of an initiative, envision what legitimate governance might look like, and determine the acceptability of management actions. After a conservation initiative is in place, perceptions can be useful for understanding the effectiveness, legitimacy, and acceptability of a conservation initiative. This might be accomplished through proactive monitoring and evaluation or occur in a reactive manner when problems emerge. For example, knowledge of perceptions may be used to understand why local people do not support an initiative so that managers can determine what went wrong and how to get it right. Perceptions may also be used to rapidly determine social and ecological status - particularly in data-deficient situations - for planning purposes or monitoring changes.

Finally, there is the question of scale. Perceptions are commonly used to examine conservation at single sites. However, they can also be used to examine and compare questions related to social impacts, ecological outcomes, governance, and management across multiple sites in a region or country (Marcus 2001; Bennett \& Dearden 2014a) or even for multiple conservation initiatives in different countries (Tobey \& Torell 2006; Turner et al. 2014). Such broader-scale use of knowledge of perceptions allows for insights into how to improve national or international conservation policies. Developing comprehensive big-picture lessons for conservation policy may require using sampling methods akin to quantitative surveys ( e.g., random sampling of representatives from particular stakeholder groups across a select number of sites) combined with rigorous qualitative analysis or semiquantitative methods (e.g., qualitative 
comparative analysis). General lessons learned may also be gleaned from literature reviews of numerous qualitative studies of perceptions or through qualitative systematic reviews.

\section{Broader evidence to increase conservation success}

Perceptions provide insight and are an indispensable form of evidence that deserves a central place in the toolkit for monitoring, evaluating, and adapting conservation programs and policies. Qualitative and quantitative perceptions-based studies are more efficient, holistic, and better able to address some questions than the alternatives and provide critical insights into how to engender support and improve conservation effectiveness. In particular, knowledge of perceptions can help one understand local evaluations of the social impacts and ecological outcomes of conservation, the legitimacy of conservation governance, and the acceptability of management actions. Local perceptions can affect local support for conservation and determine whether individuals will take actions that facilitate or undermine conservation initiatives and outcomes (Figure 1). They can be studied prior to implementing a conservation initiative to establish baselines and determine appropriate courses of action or after a project is underway to monitor outcomes and emerging issues. Perceptions can also help determine interventions at scales ranging from management of individual protected areas to international conservation policies when suitable methods are applied.

I am not arguing for the primacy of perceptions-based studies vis-à-vis other conservation science approaches. Yet evidence-based conservation needs to embrace a broader perspective and array of methods than evaluations that emerge from the natural science and econometric traditions of examining conservation policies and actions. Better incorporation of the social sciences and a plurality of methods will provide a more complete picture on which to base management decisions. Perceptions can and should be integrated with other forms of evidence as part of robust monitoring and evaluation protocols. This information can then be communicated and incorporated into deliberative policy making and adaptive management for conservation. Moreover, the conservation community needs to ensure that it is clear about what it is measuring and why and that the focus is not just on monitoring but also on communicating results, deliberating on courses of action, and taking concrete steps to improve conservation outcomes.

\section{Acknowledgments}

I was supported by SSHRC and Banting Postdoctoral Fellowships from the Social Science and Humanities Research Council of Canada, a Liber Ero Fellowship in Conservation Science and a Fulbright Visiting Scholar Award at the University of Washington during various stages of the writing of this manuscript. Any opinions, findings, omissions or recommendations in this paper are those of the author alone.

\section{Literature Cited}

Adams, W. M., and C. Sandbrook. 2013. Conservation, evidence and policy. Oryx 47:329-335. Agrawal, A., and K. Redford. 2006. Poverty, development, and biodiversity conservation: shooting in the dark? World Conservation Society, New York.

Ajzen, I. 1991. The theory of planned behavior. Organizational Behavior and Human Decision Processes 50:179-211. 
Andam, K. S., P. J. Ferraro, K. R. E. Sims, A. Healy, and M. B. Holland. 2010. Protected areas reduced poverty in Costa Rica and Thailand. Proceedings of the National Academy of Sciences 107:9996-10001.

Bennett, N. J. 2015. Governing marine protected areas in an interconnected and changing world. Conservation Biology 29:303-306.

Bennett, N. J., and P. Dearden. 2014a. Why local people do not support conservation: Community perceptions of marine protected area livelihood impacts, governance and management in Thailand. Marine Policy 44:107-116.

Bennett, N. J., and P. Dearden. 2014b. From measuring outcomes to providing inputs: Governance, management, and local development for more effective marine protected areas. Marine Policy 50:96-110.

Bennett, N. J., H. Govan, and T. Satterfield. 2015. Ocean grabbing. Marine Policy 57: 61-68.

Bennett, N. J., and R. Roth. 2015. The conservation social sciences: what? how? and why? Canadian Wildlife Federation and Institute for Resources, Environment and Sustainability, University of British Columbia, Vancouver.

Bennett, N., R. H. Lemelin, and S. Ellis. 2010. Aboriginal and local perspectives on the community benefits of conservation: a case study of a proposed Canadian national park and the Lutsel K'e Dene First Nation. Geography Research Forum 30:105-134.

Bennett, N., R. H. Lemelin, R. Koster, and I. Budke. 2012. A capital assets framework for appraising and building capacity for tourism development in aboriginal protected area gateway communities. Tourism Management 33:752-766.

Berkes, F. 1999. Sacred ecology: traditional ecological knowledge and resource management. Taylor \& Francis, Philadelphia.

Berkes, F., J. Colding, and C. Folke. 2000. Rediscovery of traditional ecological knowledge as adaptive management. Ecological Applications 10:1251-1262.

Berlanga, M., and B. B. Faust. 2007. We thought we wanted a reserve: one community's disillusionment with government conservation management. Conservation and Society 5:450-477.

Biggs, D., N. Abel, A. T. Knight, A. Leitch, A. Langston, and N. C. Ban. 2011. The implementation crisis in conservation planning: could "mental models" help? Conservation Letters 4:169-183.

Borrini-Feyerabend, G., N. Dudley, T. Jaeger, B. Lassen, N. Pathak Broome, A. Philips, and T. Sandwith. 2013. Governance of protected areas: From understanding to action. International Union for Conservation of Nature, Gland, Switzerland.

Borrini-Feyerabend, G., M. Pimbert, M. T. Farvar, A. Kothari, and Y. Renard. 2007. Sharing power: Learning-by-doing in co-management of natural resources throughout the world. Earthscan, London.

Brockington, D., J. Igoe, and K. Schmidt-Soltau. 2006. Conservation, human rights, and poverty reduction. Conservation Biology 20:250-252.

Bunce, L., P. Townsley, R. Pomeroy, and R. Pollnac. 2000. Socioeconomic manual for coral reef management. Global Coral Reef Monitoring Network, Australian Inst. Marine Science, Townsville.

Cattermoul, B., P. Townsley, and J. Campbell. 2008. Sustainable livelihoods enhancement and diversification: A manual for practitioners. International Union for the Conservation of Nature, Gland, Switzerland. 
CBD (Convention on Biological Diversity). 2004. Programme of work on protected areas. C BD, Montreal. Available from http://www.cbd.int/protected/pow/learnmore/intro/ (accessed February 2015).

CBD (Convention on Biological Diversity). 2010. Aichi biodiversity targets. CBD, Montreal. Available from http://www.cbd.int/sp/targets (accessed March 2013).

Chevalier, J. M., and D. J. Buckles. 2013. A handbook for participatory action research, Monitoring and Evaluation. SAS2, Ottawa, Ontario.

Christie, P. 2005. Observed and perceived environmental impacts of marine protected areas in two Southeast Asia sites. Ocean \& Coastal Management 48:252-270.

Chuenpagdee, R., J. J. Pascual-Fernández, E. Szeliánszky, J. Luis Alegret, J. Fraga, and S. Jentoft. 2013. Marine protected areas: Re-thinking their inception. Marine Policy 39:234240.

Cinner, J. E., T. Daw, C. Huchery, P. Thoya, A. Wamukota, M. Cedras, and C. Abunge. 2014. Winners and losers in marine conservation: fishers' displacement and livelihood benefits from marine reserves. Society \& Natural Resources 27:994-1005.

Clayton, S., C. Litchfield, and E. S. Geller. 2013. Psychological science, conservation, and environmental sustainability. Frontiers in Ecology and the Environment 11:377-382.

Coad, L., A. Campbell, L. Miles, and K. Humphries. 2008. The costs and benefits of protected areas for local livelihoods: a review of the current literature. Working Paper. United Nations Environment Program World Conservation Monitoring Centre.

Cook, C. N., H. P. Possingham, and R. A. Fuller. 2013. Contribution of systematic reviews to management decisions. Conservation Biology 27:902-915.

Corson, C., and K. I. MacDonald. 2012. Enclosing the global commons: the convention on biological diversity and green grabbing. Journal of Peasant Studies 39:263-283.

Dalton, T., G. Forrester, and R. Pollnac. 2012. Participation, process quality, and performance of marine protected areas in the wider Caribbean. Environmental Management 49:12241237.

Daw, T. M., J. Robinson, and N. A. J. Graham. 2011. Perceptions of trends in Seychelles artisanal trap fisheries: comparing catch monitoring, underwater visual census and fishers' knowledge. Environmental Conservation 38:75-88.

de Snoo, G. R. et al. 2013. Toward effective nature conservation on farmland: making farmers matter. Conservation Letters 6:66-72.

Drew, J. A. 2005. Use of traditional ecological knowledge in marine conservation. Conservation Biology 19:1286-1293.

Eagles, P. F. J., F. Romagosa, W. C. Buteau-Duitschaever, M. Havitz, T. D. Glover, and B. McCutcheon. 2013. Good governance in protected areas: an evaluation of stakeholders' perceptions in British Columbia and Ontario Provincial Parks. Journal of Sustainable Tourism 21:60-79.

Edgar, G. J. et al. 2014. Global conservation outcomes depend on marine protected areas with five key features. Nature 506:216-220.

Evans, K., and M. R. Guariguata. 2008. Participatory monitoring in tropical forest management: a review of tools, concepts and lessons learned. Center for International Forestry Research, Bogor, Indonesia.

Evely, A. C., I. Fazey, M. Pinard, and X. Lambin. 2008. The influence of philosophical perspectives in integrative research: A conservation case study in the Cairngorms National Park. Ecology and Society 13:52. 
Ezebilo, E. E., and L. Mattsson. 2010. Socio-economic benefits of protected areas as perceived by local people around Cross River National Park, Nigeria. Forest Policy and Economics 12:189-193.

Fazey, I., J. A. Fazey, J. G. Salisbury, D. B. Lindenmayer, and S. Dovers. 2006. The nature and role of experiential knowledge for environmental conservation. Environmental Conservation 33:1-10.

Ferraro, P. 2008. Protected areas and human well-being. economics and conservation in the tropics: a strategic dialogue. Available from http://www.rff.org/Documents/08_Tropics_Conference/Tropics_Conference_Papers/Trop ics\%20Conference_Ferraro_Protected_Areas_and_Human_Well-Being.pdf (accessed September 2012).

Ferraro, P. J., and M. M. Hanauer. 2014. Advances in measuring the environmental and social impacts of environmental programs. Annual Review of Environment and Resources 39:495-517.

Ferraro, P. J., M. M. Hanauer, D. A. Miteva, G. J. Canavire-Bacarreza, S. K. Pattanayak, and K. R. E. Sims. 2013. More strictly protected areas are not necessarily more protective: evidence from Bolivia, Costa Rica, Indonesia, and Thailand. Environmental Research Letters 8:025011.

Ferraro, P. J., and S. K. Pattanayak. 2006. Money for nothing? A call for empirical evaluation of biodiversity conservation investments. PLoS Biology 4 (e105) DOI:10.1371/journal.pbio.0040105.

Ferse, S., M. Manez Costa, K. S. Manez, D. S. Adhuri, and M. Glaser. 2010. Allies, not aliens: increasing the role of local communities in marine protected area implementation. Environmental Conservation 37:23-34.

Fortmann, L. 2008. Participatory research in conservation and rural livelihoods: Doing science together. Wiley-Blackwell, Chichester, U.K..

Fox, H. E. et al. 2012. Reexamining the science of marine protected areas: linking knowledge to action. Conservation Letters 5:1-10.

Gavin, M. C., J. McCarter, A. Mead, F. Berkes, J. R. Stepp, D. Peterson, and R. Tang. 2015. Defining biocultural approaches to conservation. Trends in Ecology \& Evolution 30:140145.

Graham, J., B. Amos, and T. Plumtree. 2003. Governance principles for protected areas in the 21 st century. Page 50. Institute on Governance, Parks Canada, and Canadian International Development Agency, Ottawa.

Gujit, I. 1999. Participatory Monitoring and Evaluation for Natural Resource Management and Research. Natural Resources Institute, Chatham, UK.

Gurney, G. G., J. Cinner, N. C. Ban, R. L. Pressey, R. Pollnac, S. J. Campbell, S. Tasidjawa, and F. Setiawan. 2014. Poverty and protected areas: An evaluation of a marine integrated conservation and development project in Indonesia. Global Environmental Change 26:98-107.

Hockings, M., S. Stolton, F. Leverington, N. Dudley, and J. Courrau. 2006. Evaluating Effectiveness: A framework for assessing the management effectiveness of protected areas2nd edition. International Union for the Conservation of Nature, Gland, Switzerland.

Johannes, R. E., M. M. R. Freeman, and R. J. Hamilton. 2000. Ignore fishers' knowledge and miss the boat. Fish and Fisheries 1:257-271. 
Jones, J. P. G. 2012. Getting what you pay for: the challenge of measuring success in conservation. Animal Conservation 15:227-228.

Kareiva, P., and M. Marvier. 2012. What Is Conservation Science? BioScience 62:962-969.

Kemf, E. 1993. Indigenous peoples and protected areas: the law of mother Earth. Earthscan, London.

Klain, S. C., R. Beveridge, and N. J. Bennett. 2014. Ecologically sustainable but unjust? Negotiating equity and authority in common-pool marine resource management. Ecology and Society 19:52.

Klöckner, C. A. 2013. A comprehensive model of the psychology of environmental behaviourA meta-analysis. Global Environmental Change 23:1028-1038.

Legge, S. 2015. A plea for inserting evidence-based management into conservation practice. Animal Conservation:in press.

Leisher, C., P. van Beukering, and L. Scherl. 2007. Nature's investment bank: How marine protected areas contribute to poverty reduction. The Nature Conservancy, Arlington, Virginia.

Leleu, K., F. Alban, D. Pelletier, E. Charbonnel, Y. Letourneur, and C. F. Boudouresque. 2012. Fishers' perceptions as indicators of the performance of Marine Protected Areas (MPAs). Marine Policy 36:414-422.

Levine, J., K. M. A. Chan, and T. Satterfield. 2015. From rational actor to efficient complexity manager: Exorcising the ghost of Homo economicus with a unified synthesis of cognition research. Ecological Economics 114:22-32.

Lockwood, M. 2010. Good governance for terrestrial protected areas: A framework, principles and performance outcomes. Journal of Environmental Management 91:754-766.

Manfredo, M. J., T. L. Teel, and A. D. Bright. 2004. Application of the concepts of values and attitudes in human dimensions of natural resources research. Pages 271-282 in M. J. Manfredo, J. J. Vaske, B. L. Bruyere, D. R. Field, and P. J. Brown, editors. Society and natural resources: a summary of knowledge. Modern Litho, Jefferson, Missouri.

Marcus, R. 2001. Seeing the Forest for the Trees: Integrated Conservation and Development Projects and Local Perceptions of Conservation in Madagascar. Human Ecology 29:381397.

Mascia, M. B., S. Pailler, M. L. Thieme, A. Rowe, M. C. Bottrill, F. Danielsen, J. Geldmann, R. Naidoo, A. S. Pullin, and N. D. Burgess. 2014. Commonalities and complementarities among approaches to conservation monitoring and evaluation. Biological Conservation 169:258-267.

Mathevet, R., and A. Mauchamp. 2005. Evidence-based conservation: dealing with social issues. Trends in Ecology \& Evolution 20:422-423.

McClanahan, T., J. Davies, and J. Maina. 2005. Factors influencing resource users and managers' perceptions towards marine protected area management in Kenya. Environmental Conservation 32:42-49.

McClanahan, T. R., and C. A. Abunge. 2015. Perceptions of fishing access restrictions and the disparity of benefits among stakeholder communities and nations of south-eastern Africa. Fish and Fisheries:online DOI: 10.1111/faf.12118.

Miteva, D. A., S. K. Pattanayak, and P. J. Ferraro. 2012. Evaluation of biodiversity policy instruments: what works and what doesn't? Oxford Review of Economic Policy 28:6992. 
Moon, K., and D. Blackman. 2014. A guide to understanding social science research for natural scientists. Conservation Biology 28:1167-1177.

Mora, C., and P. Sale. 2011. Ongoing global biodiversity loss and the need to move beyond protected areas: a review of the technical and practical shortcomings of protected areas on land and sea. Marine Ecology Progress Series 434:251-266.

Munhall, P. L. 2008. Perception. The SAGE encyclopedia of qualitative research methods. SAGE, Thousand Oaks, CA. Available from http://knowledge.sagepub.com/view/research/n314.xml (accessed March 2015).

Oracion, E. G., M. L. Miller, and P. Christie. 2005. Marine protected areas for whom? Fisheries, tourism, and solidarity in a Philippine community. Ocean \& Coastal Management 48:393-410.

Oxford Dictionary. 2015. Perception. Available from http://www.oxforddictionaries.com/us/definition/american_english/perception (accessed March 2015).

Pascual, U., J. Phelps, E. Garmendia, K. Brown, E. Corbera, A. Martin, E. Gomez-Baggethun, and R. Muradian. 2014. Social equity matters in payments for ecosystem services. BioScience 64:1027-1036.

Pfeifer, M., N. D. Burgess, R. D. Swetnam, P. J. Platts, S. Willcock, and R. Marchant. 2012. Protected areas: Mixed success in conserving East Africa's evergreen forests. PLoS ONE 7 (e39337) DOI: 10.1371/journal.pone.0039337.

Pilgrim, S., and J. N. Pretty. 2010. Nature and Culture: Rebuilding Lost Connections. Earthscan, London.

Pomeroy, R. S., J. E. Parks, and L. M. Watson. 2004. How is your MPA doing?: A guidebook of natural and social indicators for evaluating marine protected area management effectiveness. International Union for the Conservation of Nature, Gland, Switzerland.

Pullin, A. S., and N. Salafsky. 2010. Save the whales? Save the rainforest? Save the data! Conservation Biology 24:915-917.

Pullin, A. S., W. Sutherland, T. Gardner, V. Kapos, and J. E. Fa. 2013. Conservation priorities: identifying need, taking action and evaluating success. Key Topics in Conservation Biology 2:3-22.

Rönnbäck, P., B. Crona, and L. Ingwall. 2007. The return of ecosystem goods and services in replanted mangrove forests: perspectives from local communities in Kenya. Environmental Conservation 34:313-324.

Satterfield, T., M. Kandlikar, C. E. H. Beaudrie, J. Conti, and B. Herr Harthorn. 2009. Anticipating the perceived risk of nanotechnologies. Nature Nanotechnology 4:752-758.

Schreckenberg, K., I. Camargo, K. Withnall, C. Corrigan, P. Franks, D. Roe, L. M. Scherl, and V. Richardson. 2010. Social assessment of conservation initiatives: A review of rapid methodologies. Page 139. Report of Social Assessment of Protected Areas Initiative 22, Natural Resource Issues. International Institute for Environment and Development, London.

Schultz, P. W. 2011. Conservation means behavior. Conservation Biology 25:1080-1083.

Segan, D. B., M. C. Bottrill, P. W. J. Baxter, and H. P. Possingham. 2011. Using conservation evidence to guide management. Conservation Biology 25:200-202.

Silvano, R. A. M., S. Udvardy, M. Ceroni, and J. Farley. 2005. An ecological integrity assessment of a Brazilian Atlantic Forest watershed based on surveys of stream health 
and local farmers' perceptions: implications for management. Ecological Economics 53:369-385.

Slovic, P. 2000. The perception of risk. Earthscan, London.

SOCMON. 2015. Global Socioeconomic Monitoring Initiative for Coastal Management. Available from http://www.socmon.org (accessed March 2015).

Stern, P. C. 2000. New environmental theories: toward a coherent theory of environmentally significant behavior. Journal of Social Issues 56:407-424.

Sutherland, W. 2003. Evidence-based conservation. Conservation in Practice 4:39-42.

Sutherland, W. J., A. S. Pullin, P. M. Dolman, and T. M. Knight. 2004. The need for evidencebased conservation. Trends in Ecology \& Evolution 19:305-308.

Svensson, P., L. D. Rodwell, and M. J. Attrill. 2010. The perceptions of local fishermen towards a hotel managed marine reserve in Vietnam. Ocean \& Coastal Management 53:114-122.

Tobey, J., and E. Torell. 2006. Coastal poverty and MPA management in mainland Tanzania and Zanzibar. Ocean \& Coastal Management 49:834-854.

Turner, R. A., C. Fitzsimmons, J. Forster, R. Mahon, A. Peterson, and S. M. Stead. 2014. Measuring good governance for complex ecosystems: Perceptions of coral reefdependent communities in the Caribbean. Global Environmental Change 29:105-117.

Walker, B. L. E., and M. A. Robinson. 2009. Economic development, marine protected areas and gendered access to fishing resources in a Polynesian lagoon. Gender, Place \& Culture: A Journal of Feminist Geography 16:467-484.

Webb, E. L., R. Mailiao, and S. V. Siar. 2004. Using local user perceptions to evaluate outcomes of protected area management in the Sagay Marine Reserve, Philippines. Environmental Conservation 31:138-148.

Webler, T., S. Danielson, and S. Tuler. 2009. Using Q method to reveal social perspectives in environmental research. Page 54. Social and Environmental Research Institute, Greenfield MA.

Weeratunge, N., C. Béné, R. Siriwardane, A. Charles, D. Johnson, E. H. Allison, P. K. Nayak, and M.-C. Badjeck. 2014. Small-scale fisheries through the wellbeing lens. Fish and Fisheries 15:255-279.

West, P., J. Igoe, and D. Brockington. 2006. Parks and peoples: The social impact of protected areas. Annual Review of Anthropology 35:251-277.

Wilkie, D., and J. Ginsberg. 2014, February 27. Why Adoption of the Medical Model Would Cure Conservation Impact Evaluation. Conservation: The source for environmental intelligence. University of Washington, Seattle.

Xu, J., L. Chen, Y. Lu, and B. Fu. 2006. Local people's perceptions as decision support for protected area management in Wolong Biosphere Reserve, China. Journal of Environmental Management 78:362-372.

Yasué, M., L. Kaufman, and A. C. J. Vincent. 2010. Assessing ecological changes in and around marine reserves using community perceptions and biological surveys. Aquatic Conservation: Marine and Freshwater Ecosystems 20:407-418. 